\title{
DESIGN OF A LOW COST TEMPERATURE CONTROLLER FOR HIGH TEMPERATURE FURNACES USED IN CRYSTAL GROWTH
}

\author{
Shahera S. Patel ${ }^{1}$, D.R.Patil ${ }^{2}$, B. H. Brahmbhatt ${ }^{3}$ \\ ${ }^{1}$ Assistant Professor, Department of Electronics, S.V.University, V.V.Nagar.388120 Gujarat, India \\ ${ }^{2}$ Head,Department of Physics, R.L.College, Parola, Jalgaon, Maharashtra, India \\ ${ }^{3}$ E.M.Operator, Department of Physics, S.P. University, V.V.Nagar.388 120 Gujarat, India
}

\begin{abstract}
Temperature plays a very vital role in proper growth of crystals and compound semiconducting materials. Temperature also affects the properties of the materials. Therefore, it is desirable to accurately monitor and control the temperature of the furnace used for Growth of different types of Materials. This paper focuses on the design and construction of a low cost temperature controller for high temperature laboratory based furnaces used for crystal growth. It can also be used for industrial furnaces. The design is based on microcontroller (IC PIC16F873A). In the circuit K-type thermocouple is used as a temperature sensor. Suitable instrumentation and signal conditioning circuit is developed to give desired electrical signal to the microcontroller which is equivalent to the actual temperature. The actual temperature is monitored continuously. Because different materials have different melting points, facility is provided to program different temperature profiles. When the device exceeds a preset temperature level, power output of the circuit is switched OFF, hence switching of the heating device (Furnace).
\end{abstract}

The developed circuit is reliable and cost effective. It has good accuracy better than $\pm l o C$.The overall performance of the controller is tested and found it perfectly functional.

Keywords: Crystal Growth, Compound Semiconductor, Temperature Controller, Thermocouple.

\section{INTRODUCTION}

Temperature is most often and commonly measured environmental quantities which corresponds to primary sensations- Degree of coldness and hotness. This is due to the fact that most electronic, chemical, biological, mechanical and physical systems are more or less affected by temperature. In many cases, some processes perform better within a range of temperature[1]. Also some industrial and metallurgical applications and even electronic circuits do better within limited temperature ranges. When the needs to optimize these processes arose, the systems used for controlling the temperature within defined limits are then needed.

The temperature control systems is increasingly playing an important role in industrial production as well is in research laboratories. Recently, lots of researches have been investigated for the temperature control system based on various control strategies[2].

In metallurgical industries, furnace is the most important thermal equipment used. As well in the laboratories, material scientist uses the high temperature furnace to grow crystal, compound semiconducting materials and metal oxides etc. Hence some basic methods have been recognized for automatic control of furnace temperature, because control focus has moved to performance optimization. To design products and components that perform reliably at the temperature found in actual operating environments, it is necessary to develop a detailed understanding of how material properties and behavior changes with temperature rise and fall. High temperature furnaces are a vital component of these test configurations. They offer the functionality operators need to generate accurate data and a convenient design that optimizes productivity in the lab.

The aim of the present study is to design and develop low cost automatic temperature controller which is built around microcontroller IC PIC16F873A.

\section{SYSTEM DESIGN \&IMPLEMENTATION}

This section will discuss the design aspects of the controller. The block diagram of the developed model is as shown in Fig.1 


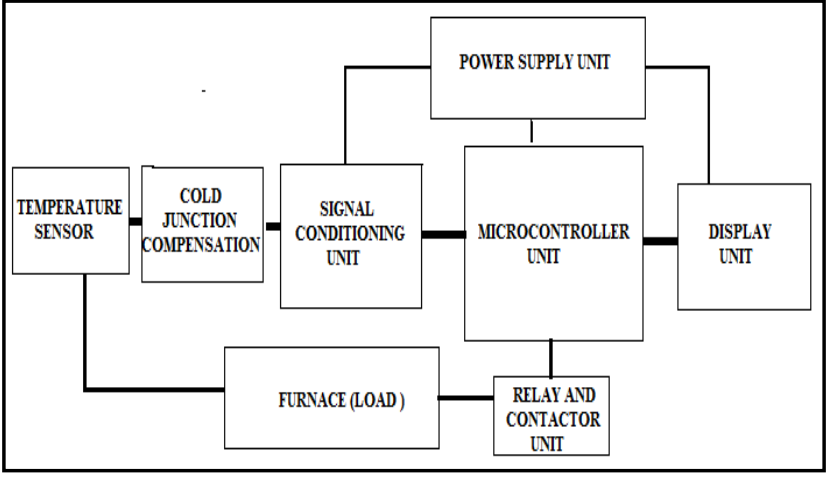

Fig-1: Block diagram of the Furnace Temperature Controller

The constituents of a furnace temperature control system are divided into the following:

(a) Power supply unit

(b) Temperature sensor : K-type thermocouple

(c) Cold junction compensation and Signal conditioning circuit

(d) Relay and contactor unit

(e) Complete Circuit Schematic

\section{DETAIL DESCRIPTION OFEXPERIMENTAL}

\section{PART}

\subsection{Power Supply Unit}

The schematic of power supply is as shown in Fig.2. The output of the circuit is $\pm 12 \mathrm{~V}$ and $+5 \mathrm{~V}$ respectively which is used to operate signal conditioning circuit and microcontroller IC respectively. The power supply unit includes,

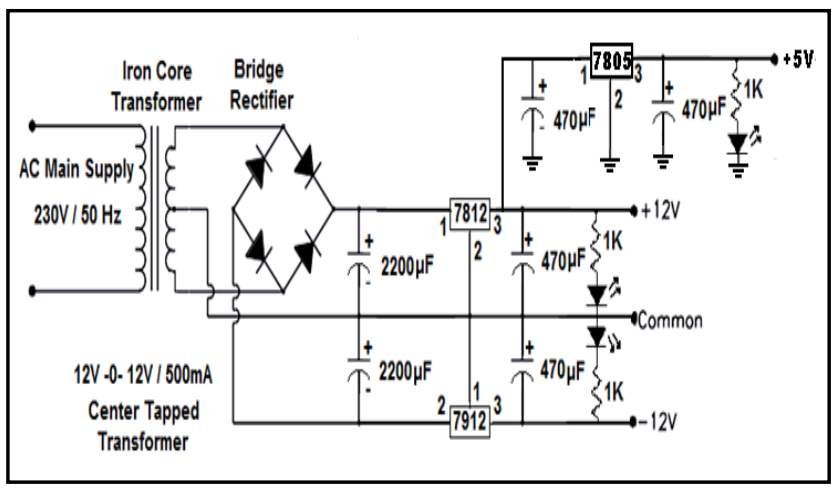

Fig-2: The Schematic of Power Supply Unit

(i)Transformer Section: which converts $230 \mathrm{~V} / 50 \mathrm{~Hz}$ AC mains supply to $12 \mathrm{~V}$ AC using $0-12 \mathrm{~V}, 500 \mathrm{~mA}$ step-down transformer.

(ii)Rectifier: The stepped down 12VAC supply is rectified using bridge rectifier to get pulsating $12 \mathrm{VDC}$.
(iii)Filter section: The capacitor of $2200 \mu \mathrm{F} / 63 \mathrm{~V}$ is connected at the $\mathrm{o} / \mathrm{p}$ of the bridge rectifier to filter out the unwanted ripple from $12 \mathrm{~V}$ pulsating DC.

(iv)Regulator: IC 7812 is used as a regulator. +ve terminal of the capacitor is connected to pin 1 (input) of IC7812.pin 2 is grounded and from pin 3 we get $+12 \mathrm{~V}$ supply. IC 7912 is used as a regulator. -ve terminal of the capacitor is connected to pin 2 (input) of IC7912.pin 1 is grounded and from pin 3 we get $-12 \mathrm{~V}$ supply. Output of IC 7812 is connected to pin 1(input) to regulator IC 7805 .A $470 \mu \mathrm{F} / 25 \mathrm{~V}$ capacitor is used at the input and output of the regulator to get smooth $+5 \mathrm{~V} \mathrm{DC}$ at pin 3 (output). This $+5 \mathrm{~V}$ is connected to microcontroller (IC PIC16F873A). LED's are used to indicate the presence of the supply voltage.

\subsection{Temperature Sensor Unit: K-Type Thermocouple}

A thermocouple[3] is a temperature-measuring device consisting of two dissimilar conductors that are brazed with each other at one end. It produces a voltage when the temperature is applied to this end. In the K type thermocouple (chromel $\{90 \%$ nickel and 10\% chromium\}-alumel $\{95 \%$ nickel, $2 \%$ manganese, $2 \%$ aluminium and $1 \%$ silicon\}) is the most common general purpose thermocouple with a sensitivity of approximately $41 \mu \mathrm{V} /{ }^{\circ} \mathrm{C}$ (chromel positive relative to alumel when the junction temperature is higher than the reference temperature). It is inexpensive, and having a temperature range from $-200{ }^{\circ} \mathrm{C}$ to $+1350{ }^{\circ} \mathrm{C}$. Here the temperature of the furnace is controlled upto $1200^{\circ} \mathrm{C}$.

\subsection{Cold Junction Compensation and Signal Conditioning Circuit}

Cold Junction Compensation circuit is as shown in Fig.3. mV generated with respect to the cold junction at non inverting terminal is compensated by means of temperature sensor LM335 [4] connected at inverting terminal of op-amp via series resistor. Suitable gain is provided by connecting variable resistor in feedback path of Op-Amp 1. Op-Amp 2 acts as a voltage follower.

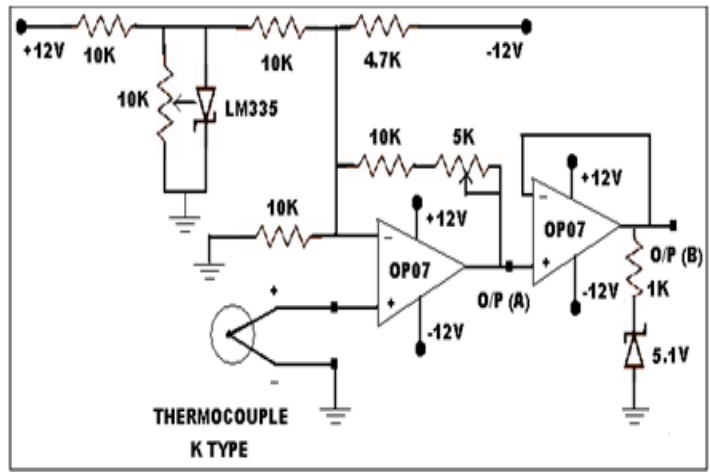

Fig-3:Cold Junction Compensation \&Signal Conditioning Circuit 


\subsection{Relay and Contactor Unit}

The connection of the relay[5] and contactor[6] circuit is shown in Fig.4

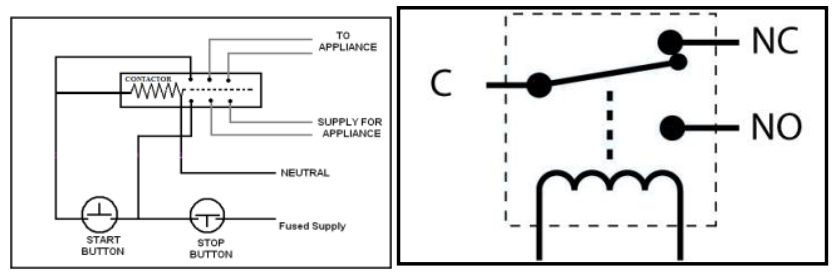

Fig-4: Relay and Contactor Connection

\subsection{Complete Circuit Schematic}

The Complete Circuit diagram of Furnace Temperature Controller is shown in Fig.5. Microcontroller PIC16F873A [7] is used to input the temperature, process it and gives an output which is connected to the display to monitor the temperature.

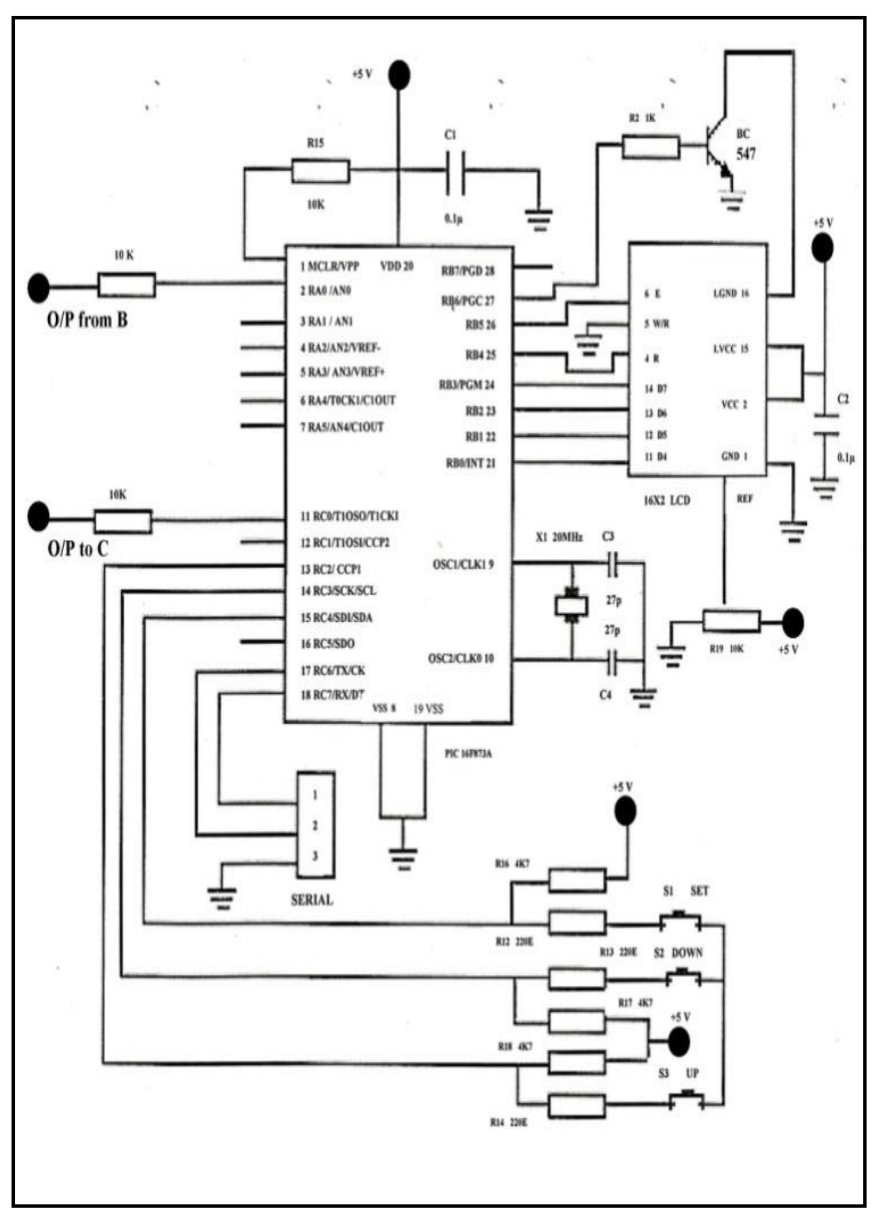

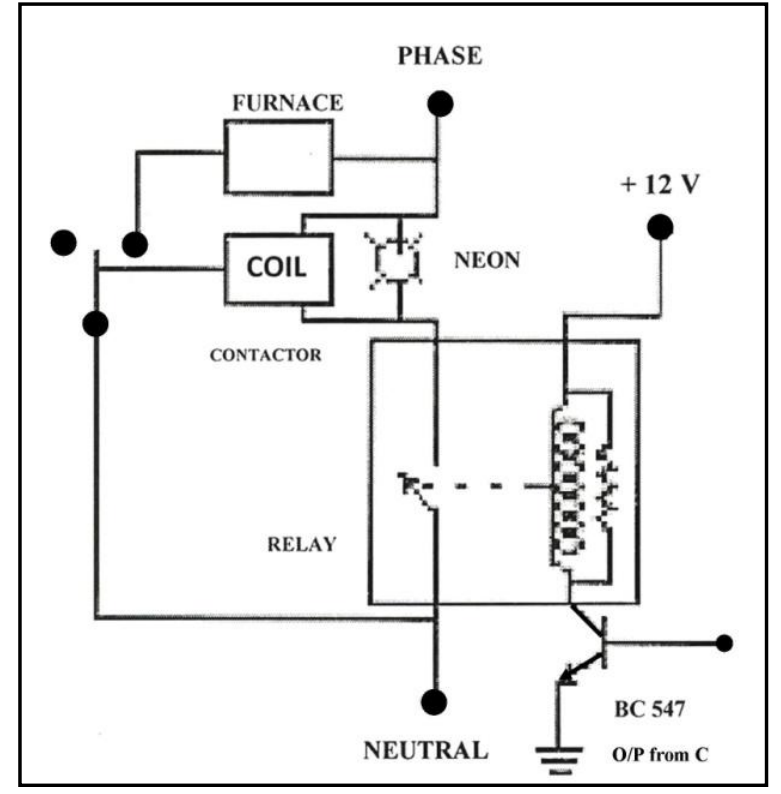

Fig-5:Complete Circuit diagram of Furnace Temperature Controller

\section{SELECTION OF THE COMPONENTS AND DETAIL ANALYSIS:}

The choice of the components involves the criteria- Cost effectiveness, easy availability and good reliability. The complete circuit is designed in a simplest way and use basic concept and widely used elemental components. The choice of the transformer used is a step down centre-tapped transformer, so as to step down the input voltage to $12 \mathrm{~V}-0$ $12 \mathrm{~V}$. For rectification purpose, three types of rectification can be possible in power supplies such as half wave rectification, full wave rectification and bridge type rectification. Here the bridge type rectification has been chosen for the conversion of A.C. voltage to D.C. voltage because the four diode bridge rectifier provides a better D.C. output voltage than Full wave rectifier.

For the success of this system the major component utilized are (1) OP07(Operational Amplifier) (2) LM335(Temperature sensor) (3) Relay and Contactor (4) Cr-Al Thermocouple(Ktype ) (5) PIC16F873A ( Microcontroller )

\subsection{IC OP07 (Operational Amplifier)}

The OP07 [8] offers excellent performance in applications requiring low offset voltage, low drift with time and temperature and very low noise. Linear IC OP-07 is interchangeable with many of the precision op-amp devices. The OP-07 also offers a wide input voltage range, high common mode rejection ratio and low input bias current. Due to these features the device use for small signal level and low frequency applications. The applications of OP07 can be used 
to amplify the signal generated from thermocouple sensor and Strain Gauge. This IC is also useful for Low level signal Processing and in Medical Instrumentation. The pin configuration of the OP07 is given below.

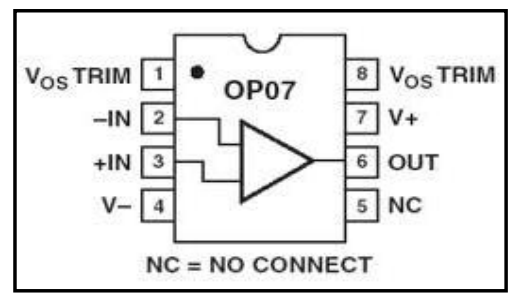

Fig-6:Pin Configuration of IC OP07

\subsection{IC LM335 (Temperature Sensor)}

The LM335 temperature sensor is an easy to use, costeffective sensor with good accuracy. The sensor is essentially a zener diode whose reverse breakdown voltage is proportional to the absolute temperature. Since the sensor is a zener diode, a bias current must be established in order to use the device. The bias circuit is as follows:

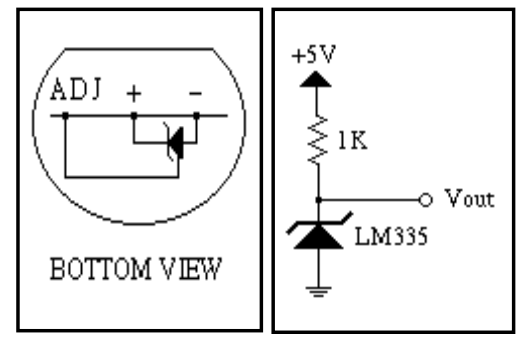

Fig-7:Pin Configuration of ICLM335

The temperature sensor's voltage output is related to absolute temperature by the following equation:

$$
\text { Vout }=\text { VoutT0 X T / T0, }
$$

Where $\mathrm{T} 0$ is the known reference temperature where VoutT0 was measured.

The nominal VoutT0 is equal to $\mathrm{T} 0 * 10 \mathrm{mV} /{ }^{\circ} \mathrm{K}$.

So, at $25^{\circ} \mathrm{C}$, Vout $\mathrm{T} 0$ is nominally $298 \mathrm{~K} * 10 \mathrm{mV} /{ }^{\circ} \mathrm{K}=2.98 \mathrm{~V}$ Thus, the voltage dropped between +5 and the diode is

$$
5 \mathrm{~V}-2.98 \mathrm{~V}=2.02 \mathrm{~V}
$$

In order to get $2 \mathrm{~mA}$ bias current, we need $1 \mathrm{~K}$ resistor for $\mathrm{R} 1$. The adj pin is not connected. The adj pin is used to trim the diode to be more accurate.

\subsection{Relay and Contactor}

A relay is an electrically operated switch. Many relays use an electromagnet to mechanically operate a switch. A simple electromagnetic relay consists of a coil of wire wrapped around a soft iron core, When an electric current is passed through the coil it generates a magnetic field that activates the armature, and the consequent movement of the movable contact(s) either makes or breaks a connection with a fixed contact. If the set of contacts was closed when the relay was de-energized, then the movement opens the contacts and breaks the connection, and vice versa if the contacts were open. Relays are used where it is necessary to control a circuit by a low-power signal (with complete electrical isolation between control and controlled circuits), or where several circuits must be controlled by one signal. A type of relay that can handle the high power required to directly control an electric motor or other loads is called a contactor.
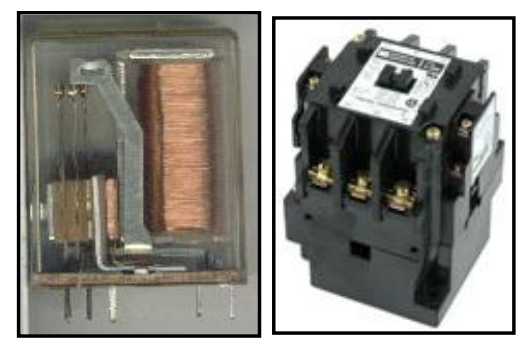

Fig-8: Relay and Contactor

\subsection{Cr-Al Thermocouple (K type)}

A thermocouple is a sensor for measuring temperature. It consists of two dissimilar metals, joined together at one end. When the junction of the two metals is heated or cooled a voltage is produced that can be correlated back to the temperature. The thermocouple alloys are commonly available as wire. A thermocouple is available in different combination of metals or calibrations. The four most common calibrations are $\mathrm{J}, \mathrm{K}, \mathrm{T}$ and $\mathrm{E}$. Each calibration has a different temperature range and environment, although the maximum temperature varies with the diameter of the wire used in the thermocouple. Details of K-type thermocouple used for this work.

- $\quad-$ K Type Thermocouple ( 14 Gauge )

- $\quad--22 \mathrm{~mm}$ Diameter ( $310 \mathrm{SS}$ tube ) Length : $1 \mathrm{ft}$

- --Head Type Thermocouple.

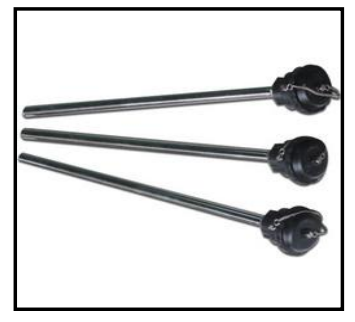

Fig-9: Thermocouple sensor (head type) 


\subsection{PIC16F873A (Microcontroller)}

The Microcontroller used here for controlling the temperature has following technical details.

Flash 28-pin 4kB Microcontroller with A/D converter, * 100,000 erase/write cycle Enhanced Flash program memory typical.

* Self-reprogrammable under software control

* Single-supply 5V In-Circuit Serial Programming

* Programmable Code Protection

Peripheral Features

* Two 8-bittimer/counter with Prescalar

* One 16-bit timer/counter

High-Performance RISC CPU

* Only 35 single-word instructions to learn

* DC-20MHz clock input

* Up to $8 \mathrm{~K}$ x 14 words of Flash Program Memory

*Pinout Compatible to other 28-pin or 40/44-pin

Analog Features

* 10-bit, up to 8-channel A-to-D Converter

* Two Analog Comparators

CMOS Technology

* Low-power, high-speed Flash/EEPROM technology

$*$ Wide operating voltage range $(2.0 \mathrm{~V}$ to $5.5 \mathrm{~V})$

\section{RESULTS,DISCUSSION AND TESTING OF}

\section{THE CIRCUIT}

Temperature plays a very vital role for good crystallization of the materials. Initially the temperature is set when the mains supply is switched ON, Furnace becomes ON which increases the temperature. Also, various materials have different melting points, it is necessary to program different temperature profiles according to the materials chosen. For this, Programming is done to get a constant rise in temperature at regular interval of time. Once the required temperature is achieved it is kept constant for few hours. Then again it is decreased for fixed time. The rate of rise and decay time is selected according the requirement, It may be same or different. The corresponding curve for temperature rise and decay is as shown in Fig.9

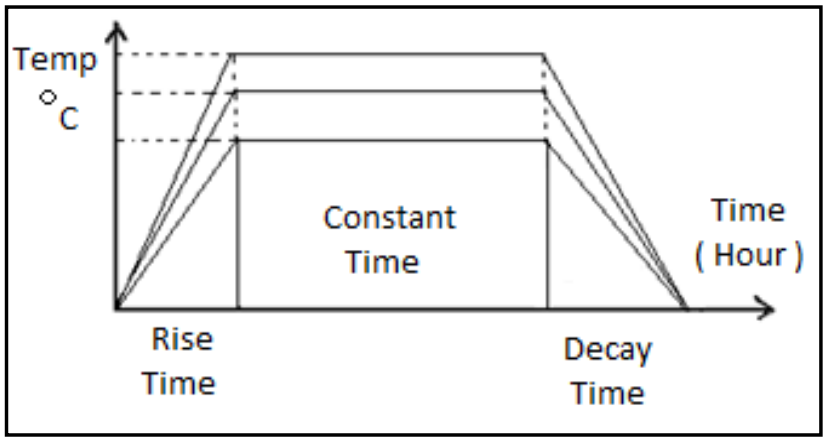

Fig-10: Temperature profile curve
One can program such different cycles. Facility is also provided to store such 10 various temperature profiles.

First individual circuit modules were fabricated and tested. Once they found working satisfactorily, the furnace was connected to the microcontroller via suitable relay and contactor circuit. Visual indication is also provided to check the status of the furnace. The performance of each module and reliability of the circuit was checked and measured and found working satisfactorily. Different materials were grown with different temperature profile and then they were characterized using electron microscopy and x-ray techniques. The results obtained was satisfactory.

\section{CONCLUSIONS}

A simple, cost effective and reliable temperature controller was designed and tested successfully. The K-type thermocouple is used as a temperature sensor. Cold junction compensation circuit is provided. The temperature of the furnace is controlled up to $1200^{\circ} \mathrm{C}$ with an accuracy of $\pm 1{ }^{\circ} \mathrm{C}$. The working of the controller is found satisfactorily.

\section{FUTURE SCOPE}

Here the developed controller is used for Single Zone Furnace. In future it is proposed to use the set of such controllers for Dual Zone Furnace.

\section{REFERENCES:}

[1]. Curtis.D.Johnson, "Process Control Instrumentation Technology," Pearson Education,2009.

[2]. A. Nagoorkani, " Control Systems,"First Edition, RBA Publications, 2002.

[3]. B.C.Nakra and K.K.Chaudhary "Instrumentation, Measurement and Analysis "Second Edition, Tata McGrawHill Education,2004

[4]. www.ti.com/product/lm335 : Temperature sensor:

[5]. Kenneth B. Rexford and Peter R. Giuliani, "Electrical control for Machines" $6{ }^{\text {th }}$ Edition,.

[6]. Ragnar Holm “Electric Contacts Handbook" $3^{\text {rd }}$ Edition, (1958)

[7].https://www.futurlec.com/Microchip/PIC16F873A.shtmlM icrocontroller

[8]. https://www.analog.com : Operational Amplifier OP07

\section{BIOGRAPHIES:}

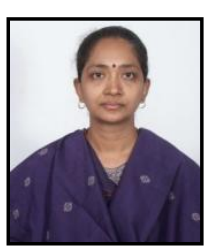

Dr.(Mrs.) ShaheraS.Patel received her B.Sc. and M.Sc. degree in Electronics from Sardar Patel University, V.V.Nagar, Gujarat, India in $1989 \& 1991$ respectively. she obtained her Ph.D. degree in Electronics in 2005 from Sardar Patel University. She has joined as Technical Officer-I in University Science Instrumentation Centre (USIC), Sardar Patel University in 
1991. At present she is working as an Assistant Professor at Department of Electronics, Sardar Patel University. Her area of interest is in Instrumentation, Nano Science, Microprocessor and Microcontroller based automatic control and automation. She has attended more than 60 International/National conferences/Seminars/Workshops. She has presented and published about 40 research papers in conferences/seminars/journals. She was honored by Hari Ohm awarded for best research paper. She is a member of ISTE, IPA, Instrument Society of India of India. She has offered her services as a reviewer for various journals. Also, she has worked as a visiting faculty and given Invited talks in conferences and in various training programmes..

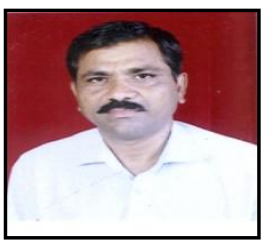

Dr. D. R.Patil Head, Department of Physics, R.L.College, Parola, Jalgaon. He has completed his Doctorate of Philosophy in 2007. His research areas are gas sensors by employing thick and thin film technology, nanotechnology and solar cell applications and related instrumentation. He has published 28 articles in national and international journals and some of his articles are ranked among the top most downloaded articles. He has presented 57 articles in various national and international conferences and also worked as a resource person. He has reviewed 28 articles and currently guiding 4 Ph.D.students. He is Life member of Indian Science Congress Association, Kolkata, India; Crystal Research Society, Anna University, Chennai,India; Society for Materials Chemistry,B.A.R.C., Trombay, Mumbai and member of Optical Society of India and R.L.Literacy Mission ( Tashil-Parola) and member of various bodies associated with social activities.

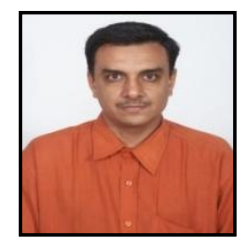

Mr. Bhavin H. Brahmbhatt received his B.Sc. degree in Physics and M.Sc. degree in Physics( Solid State Electronics ) from Sardar Patel University, V.V.Nagar, Gujarat, India in 1986 \& 1988 respectively. He has joined as Technician in University Science Instrumentation Centre (USIC), Sardar Patel University in 1989. At present he is working as an Electron Microscope Operator at Department of Physics, Sardar Patel University. His area of interest is in Instrumentation, Microprocessor and Microcontroller based automatic control and automation. He has attended several International/National conferences/Seminars/Workshops. He has published many research papers in conferences/seminars/journals. He was honored by Hari Ohm awarded for best research paper. he is a member of Indian Physics Association of India. 